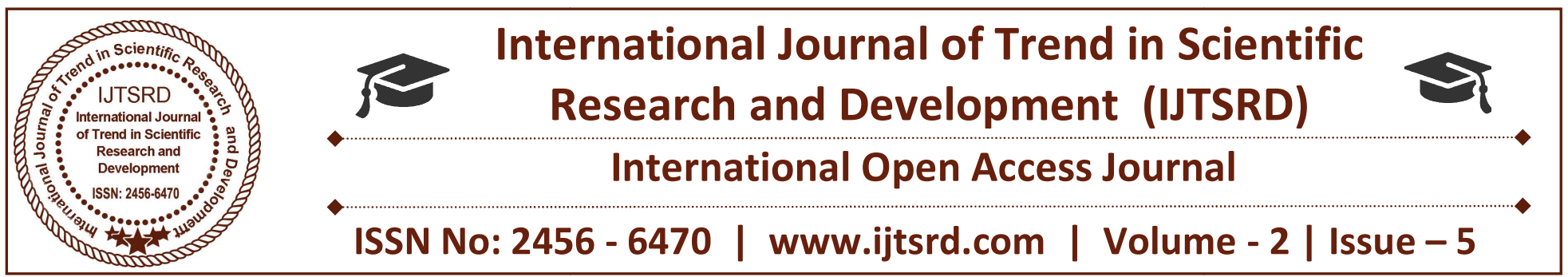

\title{
Experimental and Numerical Investigations on Melting Behavior of PCM in Storage Tank
}

\author{
Ei Ei Phyu', Mi Sandar Mon ${ }^{2}$ \\ ${ }^{1} \mathrm{Ph} . \mathrm{D}$ Student, ${ }^{2}$ Professor and Head of Mechanical Engineering Department \\ ${ }^{1,2}$ Mechanical Engineering Department, Yangon Technological University, \\ Insein Rd, Yangon, Myanmar (Burma)
}

\begin{abstract}
The present work investigates the thermal performance of storage unit using phase change material by experimentally and numerically. Commercial grade stearic acid is used as phase change material (PCM) packed in two cylindrical copper tubes and water is used as heat transfer fluid (HTF). The instantaneous temperature variations of PCM at different layers along the axial direction of the tube are experimentally measured. The PCM temperature at various mass flow rates are measured by experimentally and compared with the numerical results. It is found that the results of the experiment are in good agreement with the numerical results.
\end{abstract}

Keywords: Phase change material, Heat transfer fluid, Mass flow rate, Thermal performance

\section{INTRODUCTION}

The increasing consumption of energy and excessive use of natural resources result in the depletion of fossil fuel and pollutant emission to the environment. Therefore, new technologies of energy utilization to improve efficiency are the focuses on current and future researches. Thermal Energy storage is proposed to improve the energy efficiency, which can offset the mismatch between energy supply and energy demand in both space and time domains. Energy storage system can be classified in three main groups: sensible, latent and thermo-chemical heat storage. Latent heat thermal energy storage based on the use of phase change material (PCM) is becoming increasingly attractive due to their high storage capacity per unit volume and isothermal behaviour of its phase change during charging and discharging process.

Many researchers made numerical and experimental investigation on performance of thermal energy storage system in the past. Latent heat storage is relatively new area of research and was pioneered by Dr. Telkes in the 1940 s. It did not receive much attention. However, until the energy crisis of the late 1970s and early 1980s, PCM was first used in British trains in Trombe walls [1]. The problem of melting and solidification of PCM in a cavity has received much attention since 1990s. Phase change problems are very complex and it is very difficult of obtain the analytical solution of PCM. Since 2000s, the numerical methods are very powerful and popular for solving transient problem of phase. Voller, V. R and Prakash, C [2] developed an enthalpy formulation based fixed grid methodology for the numerical solution of convection-diffusion controlled mushy region phase change problems.

Assis et al. [3] investigated numerical and experimental study for the process of melting of paraffin wax phase change material in spherical geometry. They performed their numerical studies using the commercial code Fluent 6.0. Computational results had good agreement with experimental results. Tan et al [4] reported an experimental and numerical study of constrained melting of phase change materials (PCM) inside a spherical capsule. Hossenizadeh et al [5] numerically studied the unconstrained melting of nano-enhanced phase 
change materials (NEPCM) in a spherical container using RT27 and copper particles are based materials and nano-particles. NEPCM is filled $85 \%$ in sphere. Their numerical result was validated with other author work (Assis et al. [3]). Xia et al [6] developed an effective packed-bed thermal energy storage that contains a spherical PCM capsules. They studied the effect of the arrangement of PCM spheres and the encapsulations of the PCM on the heat transfer performance of the LTES bed. They developed a 2D numerical model via Fluent 6.2. It was validated with experimental data from Nallusmy et al [7] and the deviation of numerical and experimental results is within $3^{\circ} \mathrm{C}$. Longeon et al [8] studied a concentric heat exchanger as a latent heat TES unit. The numerical model was validated by comparison to experimental results. Xiao et al $[9,10]$ numerically and experimentally studied the heat transfer characteristics of a shell-tube latent heat storage system during heat storage (charging) and retrieval (discharging) processes.

The objective of the present work is to study the thermal performance of PCM in two cylindrical copper tubes which is placed in hot water tank by experimentally and numerically. Parametric studies are carried out to examine the effect of HTF flow rate and validate the numerical simulation with experimental results during the charging process.

\section{Experimental Setup and Procedure}

A. Experimental Setup

The experimental work has been performed in the Thermodynamic Laboratory which is situated in Building-7 of Yangon Technological University. The schematic diagram of experimental setup is shown in Figure 1.

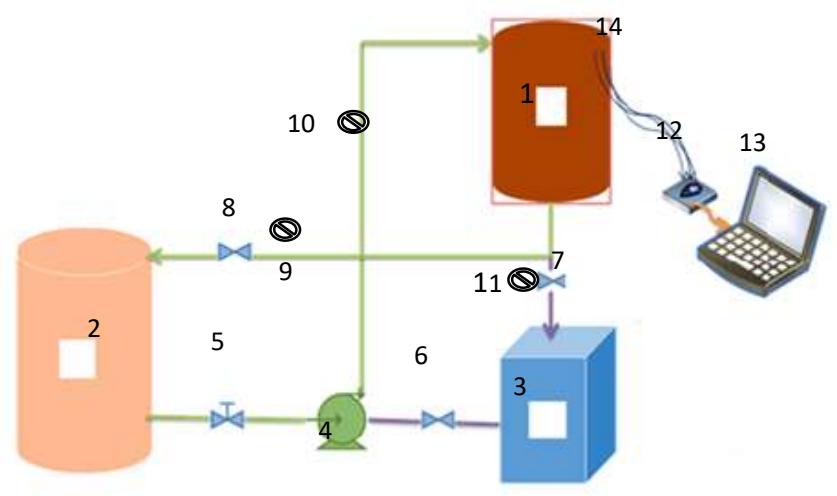

Figure1. Schematic diagram of experimental setup
The experimental facilities used in this study include: (1) energy storage unit, (2) heat source, (3) cold water storage tank, (4) centrifugal pump, (5),(6),(7) and (8) flow control valves, (9), (10), (11) rota meters, (12) thermocouples and data logger, (13) personal computer and (14) stirrer. The photographic view of the experimental setup is shown in Figure 2.

The capacity of the stainless steel tank is 48 lit (320 $\mathrm{mm}$ diameter and $600 \mathrm{~mm}$ height) and it is insulated with foam of $100 \mathrm{~mm}$ thickness. For uniform flow of heat transfer fluid flow rate (HTF), a flow distributor is provided on the top of the tank. An insulated stainless steel tank of 120 litres capacity which was fitted with $3 \mathrm{~kW}$ heaters used as heat source. The temperature of the heat source was controlled by the thermostat in the control box.

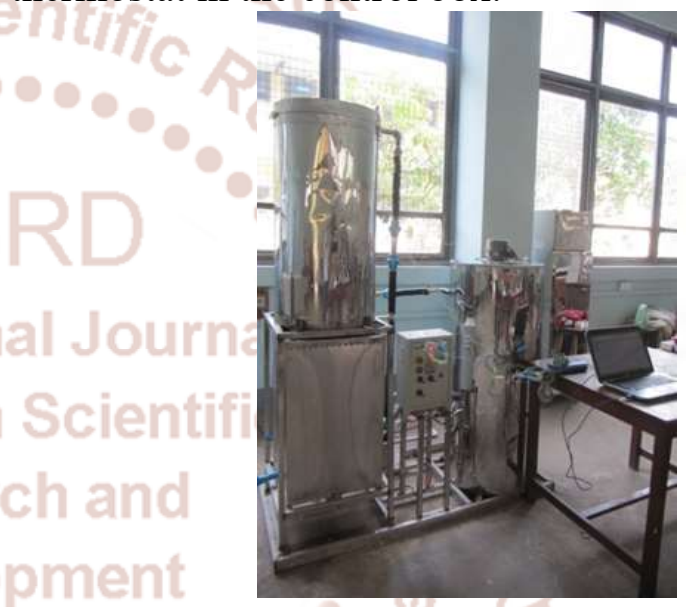

(a) Photographic view

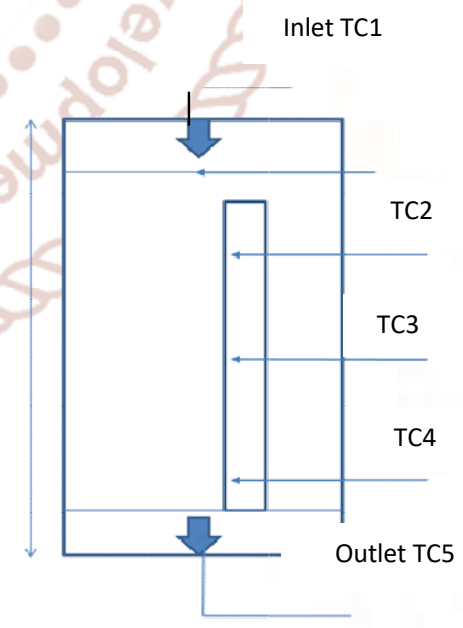

(b) Locations of thermocouples Figure2. Experimental test rig

A $0.25 \mathrm{hp}$ centrifugal pump was used during the charging process to pump the hot water (HTF) from the heater to the storage tank then back to the heater 
and during the discharging process to pump the cold water from the cold water storage tank to the energy storage tank. Three acrylic rota meters (model FL$9001)$ with the accuracy of $\pm 5 \%$ are used to measure the flow rate of heat transfer fluid. The flow control valves are used to regulate the flow rate of heat transfer fluid. The instantaneous temperature of the PCM in the storage tank is measured by using K-Type thermocouples and collected by using a data logger (USBTC-08) manufactured by PICO Technology. Three thermocouples (Top Layer (TC2), Middle Layer (TC3) and Bottom Layer (TC4)) were inserted near the centre axis of the tube along its axial direction, as shown in Figure 2. Another two thermocouples were equipped at the inlet and outlet position of the main storage tank to measure the water inlet and outlet temperature.

The PCM used in this study was commercial grade stearic acid and a melting temperature range of (51$55)^{\circ} \mathrm{C}$. Eight cylindrical copper tubes which contains $365 \mathrm{~g}$ of stearic acid in each tube was placed vertically in the storage tank. These PCM tubes with $35 \mathrm{~mm}$ in outer diameter, $550 \mathrm{~mm}$ in height and $1 \mathrm{~mm}$ thickness were uniformly packed and supported by a wire mesh. Initially, the liquid PCM was poured into the copper tubes and cooled in storage tank to $30{ }^{\circ} \mathrm{C}$ and kept for one day.

Finally, all the tubes were encapsulated with solid PCM. Only $85 \%$ of the volume of the PCM tube was filled and the left space was used for accommodating the volume expansion of PCM. Water was used as HTF. The inlet temperature of the water was kept at $65^{\circ} \mathrm{C}$ during charging process.

\section{B. Experimental Procedure}

At the beginning of the experiment, the stearic acid (PCM) inside the copper tube is in solid state. During the charging process, the hot water storage tank is heated to the required maximum inlet temperature. HTF flows from the heat source to the main storage tank (vertically from top to bottom). The HTF transfers its energy to the PCM tubes. The charging process is continued until the thermal equilibrium is attained between temperature of the HTF and PCM.

\section{MATHEMATICAL MODEL}

A. Description of Physical Model

The schematic illustration of the computational domain of the storage tank is shown in Figure 3.

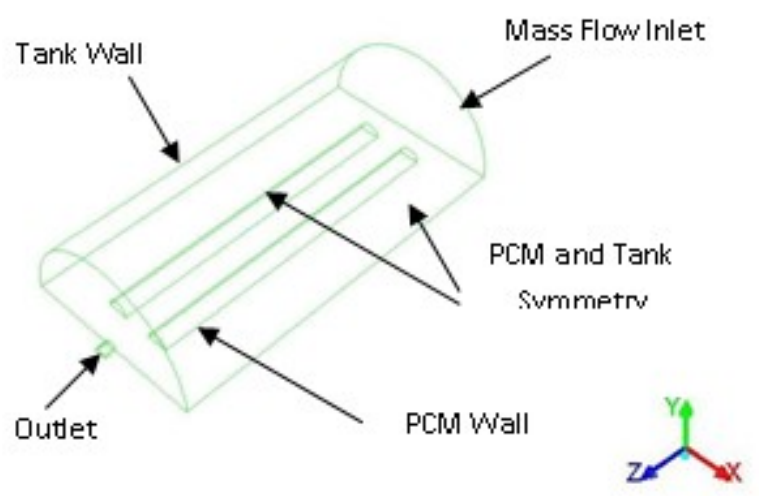

Figure3. 3D Computational Domain

Because of the complex configuration of the storage tank, the following simplifications are made in the 3D numerical model to simplify the numerical calculation:

1. The thickness of the tube is neglected due to the higher thermal conductivity of the copper with the PCM.

2. The HTF and liquid PCM are considered as incompressible Newtonian Fluid. The density of the PCM is subjected to the Bossinesq Approximation.

3. The volume change of the PCM during phase change is negligible, and the PCM is assumed homogeneous and isentropic.

4. In the numerical calculation, the thermal conductivity and heat capacity of PCM are varies piece wise linear with the temperature.

5. The initial temperature of the storage tank is constant. The inlet flow velocity and the inlet temperature of the flow velocity are also regarded as constant. The outer surface of the tank is adiabatic, so the heat loss is negligible.

A 3D numerical model is established to investigate the transient heat transfer and phase change process of PCM coupled with the HTF according to the above assumptions.

The governing equations are formulated as below; which are consisted of the continuity, momentum and energy equations:

Continuity equation:

$$
\nabla \cdot(V)=0
$$

Momentum equation:

$$
\rho \frac{\partial \stackrel{\mu}{V}}{\partial t}+\rho \stackrel{\rho}{\rho} \cdot \nabla \stackrel{\rho}{V}=-\nabla p+\rho g+\mu \nabla^{2} \stackrel{\rho}{V}+\stackrel{\rho}{S}
$$

Energy equation:

$$
\frac{\partial \rho H}{\partial t}+\nabla \cdot(\rho \stackrel{\rho}{\rho} H)=\nabla \cdot(k \nabla T)
$$


where $\rho$ is the density, $\mathrm{V}$ is the velocity of the liquid, $\mathrm{p}$ is the pressure, $\mu$ is the dynamic viscosity, $g$ is the gravity, $\mathrm{k}$ is the thermal conductivity $\mathrm{ns} \mathrm{S}$ is the momentum source term. For the PCM, besides the continuity, momentum and energy equations Fluent uses the enthalpy-porosity method to model the phase change behavior. Accordingly, enthalpy $\mathrm{H}$ in Eq. (3) represents the specific enthalpy which is the sum of sensible enthalpy and the enthalpy due to phase transition.

$$
H=H_{r e f}+\int_{T_{\text {ref }}}^{T} C_{p} d T+\gamma L
$$

Where, $H_{r e f}$ is the enthalpy at the reference temperature $T_{r e f}, \mathrm{~L}$ is the latent heat and $\gamma$ is the liquid fraction. The liquid fraction $\gamma$ is defined as:

$$
\begin{array}{ll}
\gamma=0 & \text { if } T<T_{\text {solidus }} \\
\gamma=1 & \text { if } T<T_{\text {liquidus }} \\
\gamma=\frac{T-T_{\text {solidu }} s}{T_{\text {liquidus }}-T_{\text {liquidus }}} & \text { if } \\
\hline \text { solidus } & <T<T_{\text {liquidus }}
\end{array}
$$

The enthalpy-porosity formulation treats different phases as a porous media by means of the following momentum source term S:

$$
\stackrel{\rho}{\rho}=\frac{(1-\gamma)^{2}}{\left(\gamma^{3}+\zeta\right)} A_{m u s h y} \stackrel{\rho}{V}
$$

Where $\zeta$ is a small number (approximately $10^{-3}$ ) which helps to avoid the division by zero. $A_{\text {mushy }}$ is the mushy zone constant which describes how steeply the velocity is reduced to zero when the material solidifies. Therefore, higher value of $A_{\text {mushy }}$, the melting rate of PCM will be delayed. In present work, $A_{\text {mushy }}$ value of $10^{5}$ is used.

3D numerical calculations are conducted by the commercial CFD program Fluent 14.5 in the present study, and uniform unstructured tetrahedral grids are used. The momentum and energy equations are discretized by finite volume method, SIMPLE algorithm for pressure velocity coupling and first order upwind scheme is used in the present numerical calculation. The computational grid number and times step, 697013 and $1 \mathrm{~s}$ are chosen in the present numerical simulation. The convergence criteria for residuals of continuity equation and velocity components and energy equations are set $10^{-3}, 10^{-3}$ and $10^{-6}$, respectively.

\section{B. Thermophysical properties of PCM}

The thermophysical properties of PCM are listed in Table 1 and adopted from Reference [11].
Table1. Thermophysical properties of PCM (stearic acid)

\begin{tabular}{|c|c|}
\hline Property & Values \\
\hline Melting Point $\left({ }^{\circ} \mathrm{C}\right)$ & $51-55$ \\
\hline Latent Heat $(\mathrm{kJ} / \mathrm{kg})$ & 256 \\
\hline Specific Heat Capacity & 2.3 (solid state) \\
$\left(\mathrm{kJ} / \mathrm{kg}^{\circ} \mathrm{C}\right)$ & 2.8 (liquid state) \\
\hline Density $\left(\mathrm{kg} / \mathrm{m}^{3}\right)$ & 899.3 (solid state) \\
& 854.2 (liquid state) \\
\hline Thermal Conductivity & 0.36 (solid state) \\
(W/mk) & 0.172 (liquid state) \\
\hline Dynamic Viscosity $(\mathrm{kg} / \mathrm{ms})$ & 0.0289 \\
\hline
\end{tabular}

IV. REULTS AND DISCUSSIONS

A. Experimental Temperature Evolutions of PCM

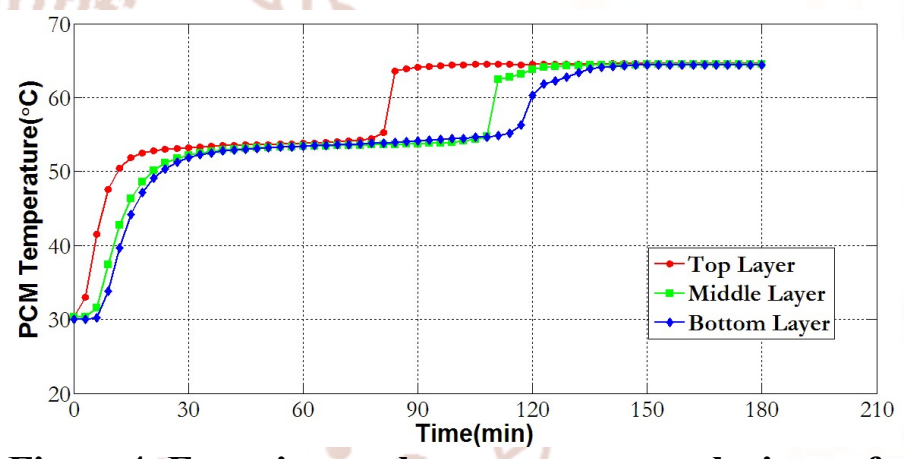

Figure4. Experimental temperature evolutions of PCM at flow rat $6 \mathrm{lit} / \mathrm{min}$

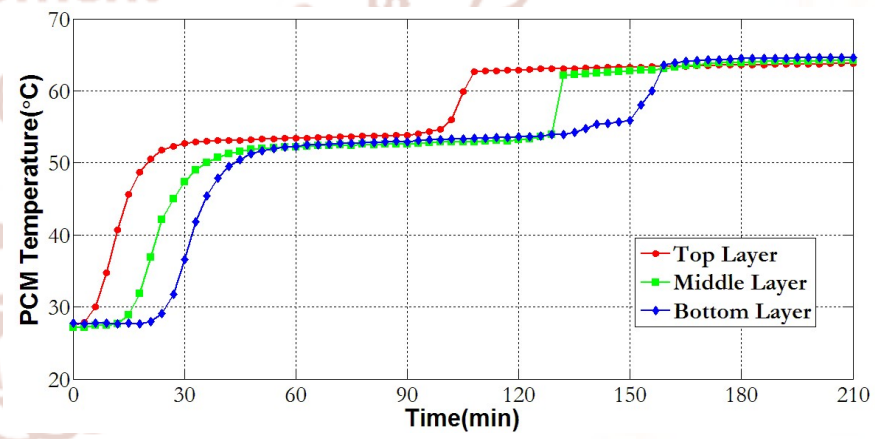

Figure5. Experimental temperature evolutions of PCM at flow rate 2 lit/min

The experimental temperature evolutions of charging process at different mass flow rates of the HTF are shown in Figure 5 and 6. It is observed that from both figures that the temperature variations of the PCM at all the layers increase with faster rate until they reach the melting temperature of PCM. After reaching the melting point $51^{\circ} \mathrm{C}$, the $\mathrm{PCM}$ temperatures remain constant until its phase change temperature range $55^{\circ}$ C. After this phase change region, the temperature of PCM increases rapidly during the heating of liquid PCM. 
In Fig. 4, it is observed that the time required for complete charging time in TC3 is shorter than in TC4, at all mass flow rates. It is also found from the both figures that the melting duration of PCM at the bottom layer take longer than the top layer. This is due to the reason that as the top mplayer is near than the bottom layer from the HTF inlet region and the boundary layer thickness is larger at the bottom layer than the top layer. Therefore, PCM in TC4 takes long time in the mushy region.

\section{B. Numerical Temperature Evolution of PCM}

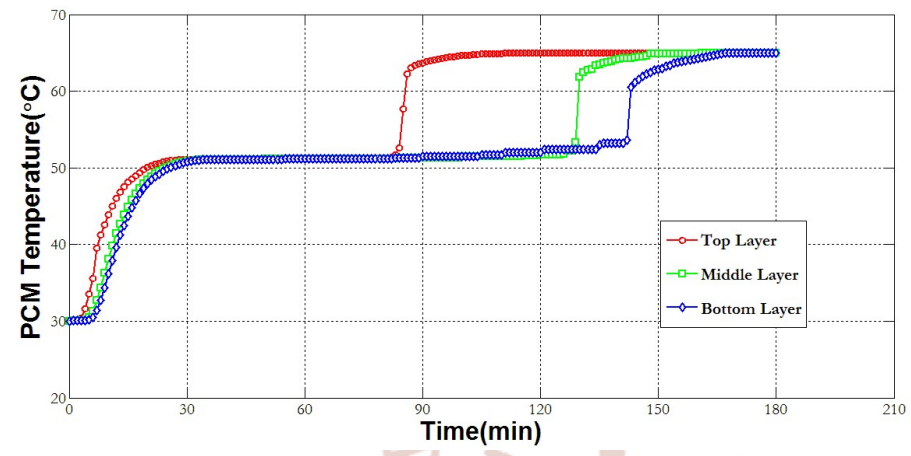

Figure6. Numerical temperature evolutions of PCM at flow rat $6 \mathrm{lit} / \mathrm{min}$

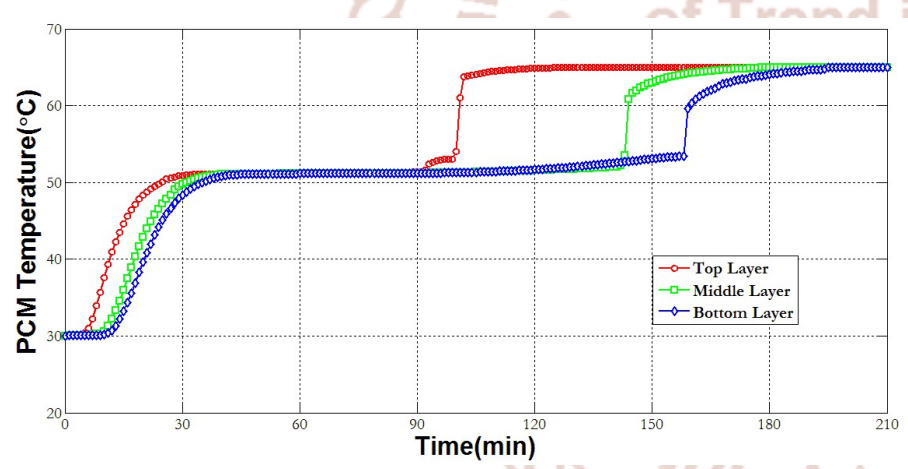

Figure7. Numerical temperature evolutions of PCM at flow rat 2 lit/min

The numerical temperature evolutions of PCM for two different mass flow rates of HTF are shown in Figure 6 and 7. In the heat charging process, the inlet temperature is $65^{\circ} \mathrm{C}$ and the initial temperature of $\mathrm{PCM}$ and $\mathrm{HTF}$ is at $30^{\circ} \mathrm{C}$.

\section{Experimental and Numerical Results Comparison}

Figure 9 and 10 shows the experimental and numerical results of the evolutions of the PCM temperature for various mass flow rates of HTF during the charging process.

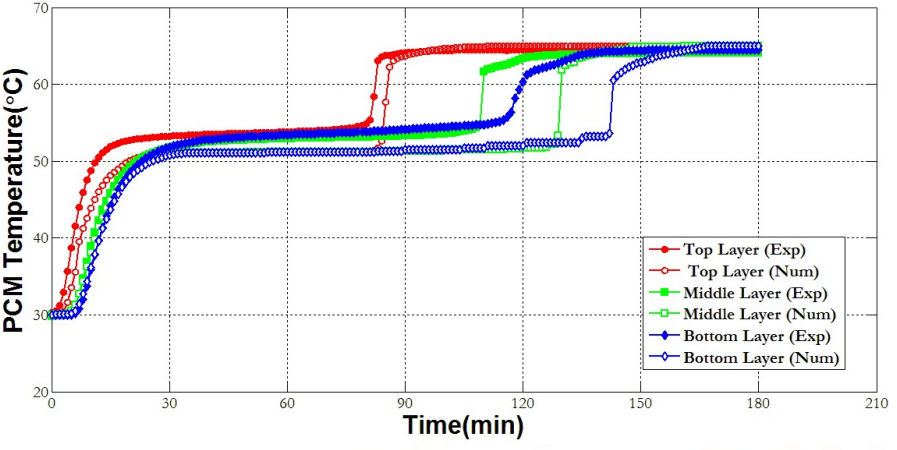

Figure8. Comparison of experimental and numerical PCM temperature for HTF flow rate 6 lit/min

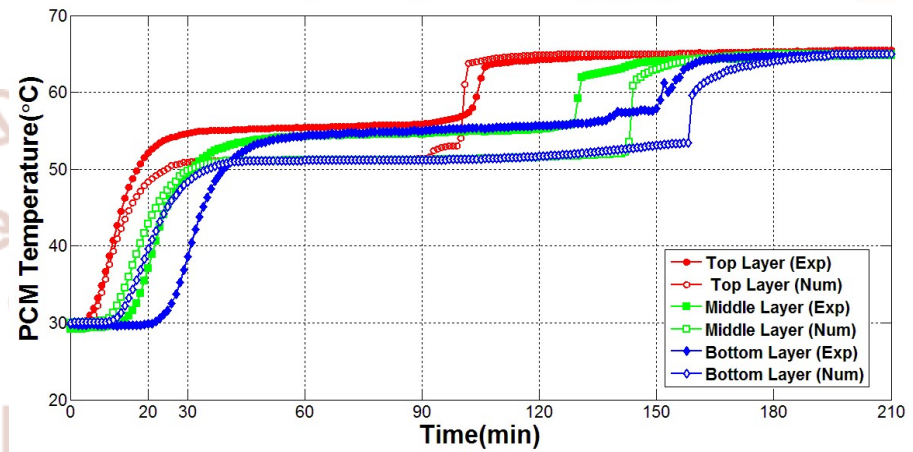

Figure9. Comparison of experimental and numerical PCM temperature for HTF flow rate 2 lit/min

We can clearly see that from both figures, an increase in mass flow rate has a large influence on the phase transition process of PCM. As the flow rate increase, the time required for complete charging becomes smaller. It is seen from the experimental temperature evolutions that charging time is decreased by $18 \%$ at bottom layer, $23 \%$ at middle layer and $21 \%$ at top layer, when the flow rate is increased from $2 \mathrm{lit} / \mathrm{min}$ to $6 \mathrm{lit} / \mathrm{min}$, where as in the case of numerical investigations, it is decreased by $19 \%$ at the bottom layer, $21 \%$ at the middle layer and $24 \%$ at the top layer.

It is also indicated from both figures that the numerical results are slight difference comparison with the experimental results. At the flow rate 2 lit/min, the total charging time a of the numerical simulation increases $9 \%$ at the top layer, $12 \%$ at the middle layer and $16 \%$ at the bottom layer than the charging time of the experimental investigations. At flow rate $6 \mathrm{lit} / \mathrm{min}$, the total charging time a of the numerical simulation increases $3 \%$ at the top layer, 13 $\%$ at the middle layer and $14 \%$ at the bottom layer than the charging time of the experimental investigations. 


\section{CONCLUSION}

In the present study, experimental and numerical investigations of PCM in storage tank are described. A series of experiments were carried out to investigate the thermal performance of PCM storage tank at different mass flow rates of HTF during the heat charging process. Meanwhile, a 3D mathematical model using enthalpy porosity and melting/solidification model was built to study the thermal performance of storage tank. It was observed that larger mass flow inlet of HTF can enhance shorten time durations of the heat charging process. The temperature evolutions of HTF and PCM in experimental results are in good agreement with the numerical results. Therefore, this numerical model is useful to predict the energy storage behavior of PCM storage tank for the different flow rates of HTF.

\section{REFERENCES}

1. Sharma, S. D., and Sagara, K. 2005. "Latent Heat Storage Materials and Systems: A Review". International Journal of Green Energy. 2, (1), pp.1-56.

2. Voller, V. R., and Prakash, C. 1987: "A Fixed Grid Numerical Modelling Methodology for Convection-Diffision Mushy Region Phasechange Problems'. International Journal of Heat and Mass Transfer. 30, (8), pp. 1709-1719.

3. Assis, E., et al. (2007). "Numerical and experimental study of melting in a spherical shell." International Journal of Heat and Mass Transfer 50(9): 1790-1804.

4. Tan, F., et al. (2009). "Experimental and computational study of constrained melting of phase change material (PCM) inside a spherical capsule." International Journal of Heat and Mass Transfer 52(15): 3464-3472.

5. Xia, L., et al. (2010). "Numerical heat transfer analysis of the packed bed latent heat storage system based on an effective packed bed model." Energy 35(5): 2022-2032.

6. Nallusamy, N., et al. (2007). "Experimental Investigation on a Combined Sensible and Latent Heat Storage System Integrated with Constant/Varying (Solar) Heat Sources." Renewable Energy 32(7): 1206-1227.

7. Hossenizadeh, S. F., et al. (2012). "Numerical investigations of unconstrained melting of nanoenhanced phase change material (NEPCM) inside a spherical container." International Journal of Thermal Sciences, 51.

8. Longeon, M., et al (2013). "Experimental and Numerical Study of Annular PCM Storage in the Presence of Natural Convection." Applied Energy 112: $175-184$.

9. Xiao, X and Zhang, P., (2015) "Numerical and experimental study of heat transfer characteristic of a shell-tube latent heat storage system: Part 1Charging process", Energy, 79, 337-350.

10. Xiao, X and Zhang, P., (2015) "Numerical and experimental study of heat transfer characteristic of a shell-tube latent heat storage system: Part IIDischarging process", Energy, 2015, 79, 337-350.

11. T. S. A. Naing, M. S. D. Mon and S.S. Nu, (2016) "Effect of flow rate of heat transfer fluid on the charging behavior of phase change material in a hot water tank", ECTI Conference. 